\title{
WestVirginiaUniversity
}

THE RESEARCH REPOSITORY @ WVU

Graduate Theses, Dissertations, and Problem Reports

2002

\section{Evaluation of two reference planes to the horizon in the natural head position}

David M. Allport

West Virginia University

Follow this and additional works at: https://researchrepository.wvu.edu/etd

\section{Recommended Citation}

Allport, David M., "Evaluation of two reference planes to the horizon in the natural head position" (2002). Graduate Theses, Dissertations, and Problem Reports. 1515.

https://researchrepository.wvu.edu/etd/1515

This Thesis is protected by copyright and/or related rights. It has been brought to you by the The Research Repository @ WVU with permission from the rights-holder(s). You are free to use this Thesis in any way that is permitted by the copyright and related rights legislation that applies to your use. For other uses you must obtain permission from the rights-holder(s) directly, unless additional rights are indicated by a Creative Commons license in the record and/ or on the work itself. This Thesis has been accepted for inclusion in WVU Graduate Theses, Dissertations, and Problem Reports collection by an authorized administrator of The Research Repository @ WVU. For more information, please contact researchrepository@mail.wvu.edu. 


\title{
EVALUATION OF TWO REFERENCE PLANES TO THE HORIZON IN THE NATURAL HEAD POSITION by \\ David M. Allport, D.D.S.
}

\begin{abstract}
Thesis submitted to the School of Dentistry West Virginia University
\end{abstract}

In partial fulfillment of the requirements for the degree of

\author{
Master of Science \\ in \\ Prosthodontics
}
Keith E. Kinderknecht D.M.D. (Chair)
Mark W. Richards D.D.S., M.S.
C. Russell Jackson D.D.S., M.S.
Mohessen Ghalichebaf D.D.S., M.S.
Morgantown, West Virginia
2002

Keywords: prosthodontics, reference planes, H.I.P. plane 


\section{ABSTRACT \\ EVALUATION OF TWO REFERENCE PLANES TO THE HORIZON IN THE NATURAL HEAD POSITION \\ By:}

\section{David M. Allport, D.D.S.}

Dental casts are mounted to dental articulators using anatomical records in order to simulate and duplicate static and dynamic interocclusal relationships. The three dimensional relationship of the maxillary arch to the transverse horizontal axis of the mandible is defined by establishing a third point of reference. The most common reference plane is the Frankfort horizontal plane, which is theoretically parallel to the horizon when the patient is in the natural head position. ${ }^{1}$ The HIP [hamular notch incisive papilla] plane has also been proposed as a true horizontal reference plane for orienting the maxillary cast to the articulator. ${ }^{2}$ The purpose of this study was to examine the relationship of the Frankfort horizontal plane and the HIP plane to the horizontal when the patient is in the natural head position. Ten subjects were evaluated in the natural head position with angular measurements made from lateral photographs and lateral skull radiographs to determine the relationship of these two reference planes to the true horizontal plane. The mean, standard deviation and coefficient variation were calculated for both reference planes. The clinical significance of this information is to verify or modify those techniques used for mounting dental casts to the dental articulator, which is used in treatment planning and laboratory procedures. 
I would like to dedicate this research to my Grandfathers' Orval Allport and Auston Crookshanks. Both these men dedicated their life working hard and taking care of their families. They mean so much to me personally and all of my accomplishments. Thank you, I love and miss you both.

To my parents, Thank you for giving me every opportunity a son could ask for and the constant support and guidance that you have provided. You have influenced me more than you probably realize. You have given me the two most important things parents can give their children-roots and wings. 


\section{ACKNOWLEDGMENTS}

I would like to take this opportunity to thank the following people:

\section{Dr. Mark W. Richards, Dr. Mohessen Ghalichebaf and Dr. Keith}

Kinderknecht, for giving me the opportunity to become a Prosthodontist. Thank you for all of your lessons on Prosthodontics, and more importantly the lessons on life. I am glad to call you my friends. Good Luck with each of your futures and may you always get what you deserve.

Dr. Russell Jackson, for serving on my committee and providing helpful input and guidance with this project.

Dr. Keith Kinderknecht, for your expertise with this topic and for always making the time to help when I needed it.

Valerie Lazuka, for all of your hard work and more importantly your friendship.

Teresa Nestor, for your willingness to always help and for making me laugh.

Angela Kopich, for all of the work you do for the department and for being such a kind-hearted and easy person to talk to (Thanks Buddy).

Drs. Henry Miller, Saeid Zeiaei, Marcos Cid, Mayur Patel, for making this program fun and educational. I have learned something from all of you. 


\section{TABLE OF CONTENTS}

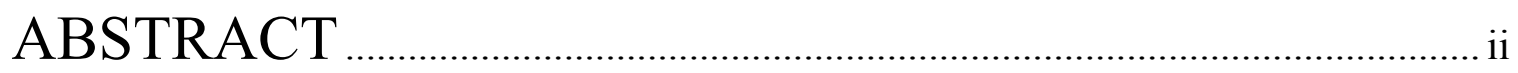

ACKNOWLEDGMENTS ………………………………………………….. iv

TABLE OF CONTENTS …………………………………………….....

LIST OF TABLES.................................................................................... vi

LIST OF FIGURES ......................................................................................... vii

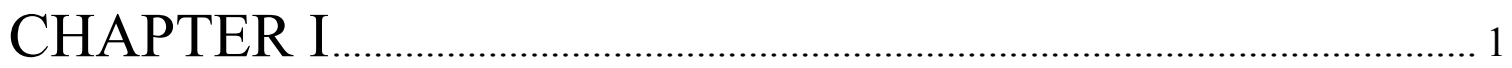

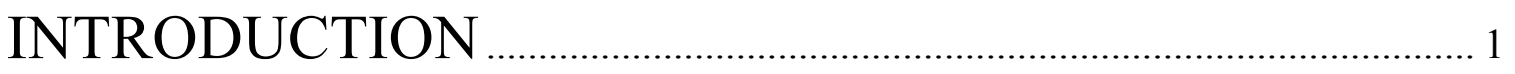

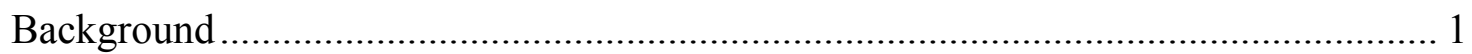

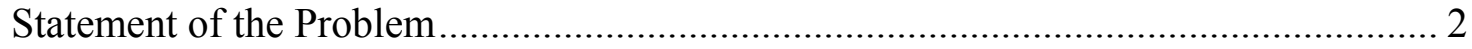

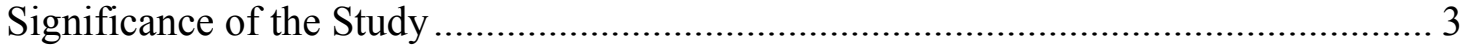

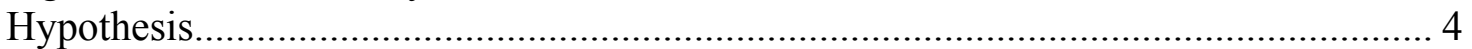

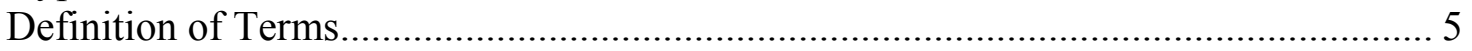

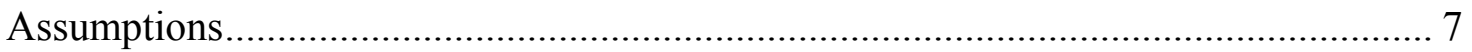

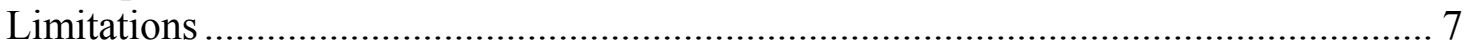

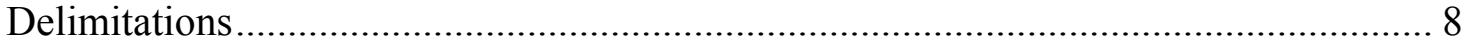

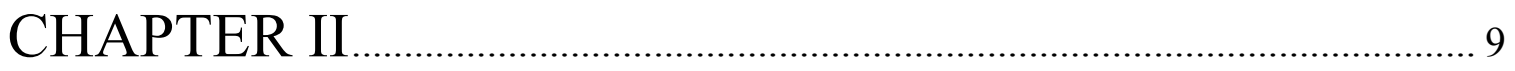

LITERATURE REVIEW ………………………………………….... 9

HISTORICAL REVIEW AND PERSPECTIVE........................................................ 9

CHAPTER III MATERIALS AND METHODS ….................... 14

CHAPTER IV …………………………………………………………. 19

RESULTS AND DISCUSSION ........................................................ 19

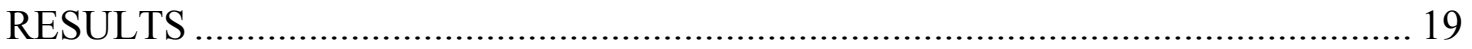

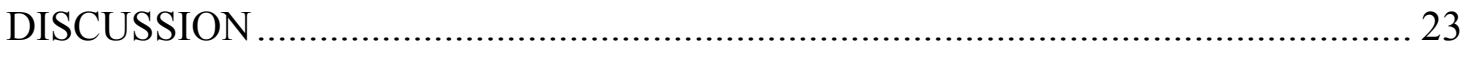

CHAPTER V ................................................................................................... 27

SUMMARY AND CONCLUSIONS …………………………......2 27

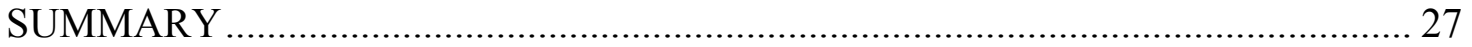

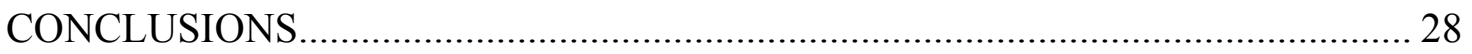

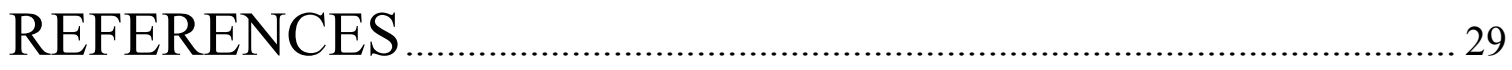

APPENDIX A ………………………………………………………………... 31

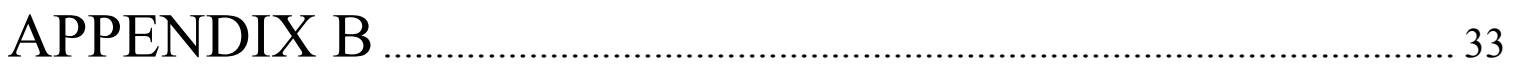

CURRICULUM VITAE .................................................................................. 35 


\section{LIST OF TABLES}

Table 1: Data Collection Sheet................................................ 21

Table 2: Means and Standard Deviations......................................22 


\section{LIST OF FIGURES}

Figure 1: Frankfort Horizontal Plane vs. True Horizontal Plane $. . . \ldots \ldots \ldots \ldots \ldots \ldots \ldots . . .22$

Figure 2: H.I.P. Plane vs. True Horizontal Plane................................23

Figure 3: H.I.P. Plane vs. Frankfort Horizontal Plane..............................23 


\section{CHAPTER I}

\section{INTRODUCTION}

\section{Background}

Accurate casts mounted to the dental articulator permit a detailed analysis of the occlusal plane and the dental occlusion. ${ }^{3}$ Diagnostic procedures can be performed for improved diagnosis and treatment planning. Tooth preparations can be rehearsed on the cast, and diagnostic-waxing procedures can be preformed for evaluation of the eventual outcome of the proposed treatment. The orientation of the maxillary arch and dentition to the instrument will effect the functional and esthetic outcome of any diagnostic or treatment procedure. ${ }^{4}$ It is common practice to orient the maxillary arch and dentition by using a face-bow record that involves a plane of reference. This plane of reference determines how the occlusal plane will be oriented within the dental articulator. The facebow transfer record for the maxillary teeth and dentition [occlusal plane] should produce the same relationship in the articulator between the occlusal plane and the upper member that is found in the patient between the occlusal plane and the surface of the earth. ${ }^{5}$ The occlusal plane is the average plane established by the incisal and occlusal surfaces of the teeth. Generally, it is not a plane but represents the planar mean of the curvature of these surfaces. ${ }^{6}$ The position of the occlusal plane in the patient and the articulator is an essential link for achieving the functional and esthetic goals of treatment. ${ }^{4}$ The use of the Frankfort horizontal plane as standard reference plane for relating the maxillary cast to the upper member of the dental articulator is well established and accepted. ${ }^{1}$ In the design 
of many articulators, there is an assumption of parallelism between the Frankfort horizontal plane, the upper member of the articulator, and the horizontal surface of the

earth. ${ }^{5}$ The use of the Frankfort horizontal plane as a reference plane for orienting maxillary casts to the dental articulator has been challenged. ${ }^{2,4,7}$ Some studies have shown that the Frankfort horizontal plane is not parallel to the surface of the earth when patients are in the natural head position. It has been suggested that the Hamular-Incisive Papilla or HIP plane is a better reference plane for orienting the maxillary cast to a dental articulator. $^{7,9}$ The premise is that the HIP Plane is parallel to the horizontal surface of the earth and that the Frankfort horizontal plane is not parallel to the horizontal surface of the earth.

The purpose of this study is to examine the relationship of Frankfort horizontal plane and the HIP plane to the surface of the earth when the patient is in the natural head position. Ten subjects will be evaluated in the natural head position with angular measurements made from lateral photographs and lateral skull radiographs to determine the relationship of these two reference planes to the true horizontal plane. The clinical significance of each reference plane and possible solutions to minimize the error when mounting diagnostic and treatment cast will be discussed.

\section{Statement of the Problem}

Is the H.I.P. Plane or the Frankfort Horizontal Plane parallel to the true horizontal plane of the surface of the earth when the subject is standing erect and assuming a natural head position? 


\section{Significance of the Study}

The goal of the mounted casts is to duplicate the patient in the dental laboratory for the purposes of diagnosis, problem solving, treatment planning, and the fabrication of dental prostheses. The orientation of the casts to the instrument is related to achieving the desired esthetic and functional results. The desired relationship can only be accomplished if the plane of reference is parallel to the surface of the earth. ${ }^{5}$ The most common reference plane used is the Frankfort horizontal plane [FH]. The Frankfort horizontal plane is defined as a horizontal plane represented in profile by a line between the lowest point on the margin of the orbit to the highest point on the margin of the auditory meatus. ${ }^{6}$ Numerous articulator systems utilize the Frankfort horizontal plane as the reference plane for orienting the maxillary arch and dentition to the upper member of the articulator. These systems assume that the FH plane is parallel to the surface of the earth and that the occlusal plane is oriented to the earth as it is in the patient. ${ }^{4}$

Many clinicians have questioned the use of the Frankfort horizontal plane as the appropriate reference plane for proper orientation of the occlusal plane within the dental articulator. ${ }^{2,4,7,8}$ The criticism is that this reference plane is not parallel to the surface of the earth and that it compromises the achievement of esthetic goals in some treatment situations.

The Hamular-incisive papilla [HIP] plane has also been proposed as the true horizontal reference plane for orienting the maxillary cast to an articulator. ${ }^{7,8}$ This plane is defined by the two hamular notches and the incisive papilla located on the hard palate. The advocates of this reference plane for orienting the occlusal plane, states that the ideal plane of occlusion should be at right angles to the forces of dental occlusion and parallel 
to the HIP plane. With the plane of occlusion parallel to the true horizontal plane of the skull, the forces are balanced along the occlusal plane and with in the cranium. Since many articulators are based on the assumption that the Frankfort plane is parallel to the true horizontal plane in the natural head position they developed a new instrument to mount dental cast called the Accu-liner. ${ }^{7}$ The Accu-liner functions as an articulator and it was designed to provide an accurate method of aligning the maxillary cast to the instrument. It is designed with the assumption of parallelism between the H.I.P. plane and

true horizontal plane. ${ }^{7}$ Currently there has been no study on the H.I.P. plane and its parallelism to the true horizontal plane in the literature. The clinical significance of this information is to verify or modify those techniques used for mounting dental casts on dental articulators that are used in esthetic and functional treatment plans and prosthodontic therapy.

\section{Hypothesis}

In the Natural head position neither the Frankfort Plane nor the H.I.P. plane is parallel to the surface of the earth [true horizontal plane]. 


\section{Definition of Terms}

Ala of Nose/Ala nasi: The wing of the nose; broad portion forming the lateral wall of each nostril. ${ }^{6}$

Anterior Reference Point: Any point located on the midface that, together with two posterior reference points, establishes a reference plane. ${ }^{6}$

Axis orbital plane : The horizontal plane established by the transverse horizontal axis of the mandible with a point on the inferior border of the right or left bony orbit (orbitale). This plane can be used as a horizontal reference point. ${ }^{6}$

Cephalometric Radiograph: A standardized radiograph of the skull. ${ }^{6}$

Cephalometric Tracing : A line drawing of structural outlines of craniofacial landmarks and facial bones, made directly from a cephalometric radiograph. ${ }^{6}$

Frankfort Horizontal Plane: Frankfort horizontal plane 1: eponym for a plane established by the lowest point in the margin of the right or left bony orbit and the highest point in the margin of the right or left bony auditory meatus 2: a horizontal plane represented in profile by a line between the lowest point on the margin of the orbit to the highest point on the margin of the auditory meatus; adopted at the 13th General Congress of German Anthropologists (the "Frankfort Agreement") at Frankfort am Main, 1882, and finally by the International Agreement for the Unification of Craniometric and Cephalometric Measurements in Monaco in 1906; called also auriculo-orbital plane, eyeear plane, Frankfort horizontal (FH), Frankfort horizontal line. ${ }^{6}$ 
Hamular Notch: Pterygomaxillary notch : the palpable notch formed by the junction of the maxilla and the pterygoid hamulus of the sphenoid bone. ${ }^{6}$

Hamular Notch-Incisive Papilla Plane: A plane extending from the hamular notches of the pterygoid hamulus to the incisive papilla. From these structures the abbreviation of the H.I.P. plane was derived. ${ }^{6}$

Horizontal plane of Reference: A horizontal plane established on the face of the patient by one anterior reference point and two posterior reference points from which measurements of the posterior anatomic determinants of occlusion and mandibular motion are made. ${ }^{6}$

Incisive Papilla: The elevation of soft tissue covering the foremen of the incisive or nasopalatine canal. ${ }^{6}$

Inferior orbital rim: A bony landmark located at the most inferior (lowest) border of the orbit of the eye. ${ }^{6}$

Natural Head Position: (also known as esthetic reference position) the position of the head when an individual is sitting or standing erect with the head level and eyes fixed on the horizon. ${ }^{6}$

Occlusal Plane: occlusal plane 1: the average plane established by the incisal and occlusal surfaces of the teeth. Generally, it is not a plane but represents the planar mean of the curvature of these surfaces 2: the surface of wax occlusion rims contoured to guide in the arrangement of denture teeth 3: a flat metallic plate used in arranging instrument similar to a facebow that indexes to the external auditory meatus and registers the relation 
of the maxillary dental arch to the external auditory meatus and a horizontal reference plane. This instrument is used to transfer the maxillary cast to the articulator. The earbow provides an average anatomic dimension between the external auditory meatus and the horizontal axis of the mandibleing denture teeth-comp to CURVE OF OCCLUSION. $^{6}$

Porion: A bony cephalometric landmark at which the nasofrontal suture is bisected by the midsagittal plane. ${ }^{6}$

Tragus: Cartilaginous projection in front of the exterior meatus of the ear. ${ }^{6}$

Tragus of Ear: That motion of a rigid body in which a straight line passing through any two points always remains parallel to its initial position. The motion may be described as a gliding or sliding position. ${ }^{6}$

\section{Assumptions}

True horizontal plane is the ideal reference plane when patients are in the natural head position.

\section{Limitations}

Radiographic distortion of the lateral skull radiograph.

Human error when finding anatomic landmarks, transposing the lines for measuring the angles and measuring the angles.

Variability of the natural head position. 


\section{Delimitations}

This in vivo study will consist of 10 fully dentate individuals with no past or present history of temporomandibular disorders or pathology. Subjects must have normal palatal anatomy for identification of landmarks, orthopedic stable relationship in maximum intercuspation, and no obvious occlusal plane discrepancies in order to participate in this study. These individuals did not undergo any invasive or irreversible procedures in this study. 


\section{CHAPTER II}

\section{LITERATURE REVIEW}

\section{HISTORICAL REVIEW AND PERSPECTIVE}

The importance of selecting a reference plane on patients for mounting casts to an articulator for the purposes of diagnosis and prosthodontic therapy is not a new idea. In fact, Foster stressed that diagnostic casts should show the relationship of the teeth to the supporting structures and the facial skeleton as a whole in order to properly diagnosis and treat occlusal problems. The maxillary cast in the articulator is the baseline from which all occlusal relationships start, and it should be positioned in the space by identifying three points, which cannot be on the same line. ${ }^{9}$ In 1955, Page wrote and explained that no jaw movements except pure opening and closing, can be duplicated by an articulator unless the upper frame is oriented to some cranial plane taken from the head. A reference plane is formed when two points located posterior to the maxillae, traditionally the right and left tempomandibular joints, and one point located anterior to them. ${ }^{10}$ In 1979 , Wilkie discussed the 5 commonly used anterior points of reference and the reasons for the use of each. He stated that the selection of the anterior point of the triangular spatial plane determines which plane in the head will become the plane of reference when the prosthesis is being fabricated. ${ }^{11}$ Gonzalez and Kingery gave three criteria in the selection of any plane of orientation (reference plane): (1) ease of location, (2) convenience, and (3) reproducibility. They stated the standard reference plane for mounting casts for analysis and the fabrication of dental prosthesis is the Frankfort horizontal plane. ${ }^{1}$ 
The Frankfort horizontal plane was originally an anthropologic reference adopted at an anthropological congress in Frankfort, Germany in 1882. In 1906, the International Agreement for the Unification of Craniometric and Cephelometric Measurement in Monaco further described the Frankfort horizontal plane as parallel to the true horizontal plane. McCollum first introduced the Frankfort horizontal plane to prosthodontics in 1939 when he developed the axis-orbital plane of orientation that he justified as being "horizontal, or near so, when the body is erect." This plane has been cited as easily accessible, well defined, and, on average, coinciding well with the true horizontal plane relative to natural head position. This concept was so widely accepted that the Glossary of Prosthodontic Terms (GPT-7) also defines the Frankfort plane as horizontal. In the design of many articulator systems there is an assumption of parallelism between the Frankfort horizontal plane, the upper member of the articulator, and the true horizontal plane. ${ }^{5}$ Studies investigating natural head position have shown that any intracranial reference planes, including the Frankfort horizontal plane, reveals a wide variation between subjects relative to the true horizontal plane. ${ }^{5}$

In a cephelometric study of 21 edentulous subjects, Gonzales and Kingery found that the axis-orbital planes and Frankfort planes were not parallel to one another, but were instead separated by an average distance of $7 \mathrm{~mm}$ between porion and the axis. To correct for this error, they suggested raising the orbital pointer by $7 \mathrm{~mm}$ above the orbital indicator on the articulator, or lowering the anterior reference point $7 \mathrm{~mm}$ on the patient. Either correction would result in an occlusal plane $7 \mathrm{~mm}$ higher in the articulator. ${ }^{1}$

In another cephleometric study of 10 subjects, Bailey and Nowlin found a difference of 7 degrees or $16 \mathrm{~mm}$ between the radiographic position of the maxillary teeth 
and the position determined by the orbital pointer. Bailey and Nowlin explained this discrepancy as being the difference between the porion and the axis. ${ }^{12}$

Stade, in a study of 10 subjects using bubble level, found the suggested $7 \mathrm{~mm}$ correction to be inadequate and indicated that $16.4 \mathrm{~mm}$ is needed to duplicate the esthetic reference position. Stade also suggested that the use of the orbitale and the axis orbitale plane may result in improper cants to the maxillary cast when it is mounted on the articulator. $^{13}$

Pichford found "Neither the Frankfort plane nor the axis orbital plane is parallel to the reference plane in the esthetic plane. The use of either plane as a reference horizontal in a face bow transfer record will place the maxillary cast too low in the articulator." ${ }^{\prime 4} \mathrm{He}$ also found in the natural head position, orbitale averages $18.5 \mathrm{~mm}$ higher than the axis, and the axis-orbital plane will form an angle of 13 degrees to the True horizontal plane. Orbitale averages $11.45 \mathrm{~mm}$ higher than the porion in the natural head position, and the Frankfort horizontal plane will form an angle of 8 degrees to the True horizontal plane. ${ }^{4}$

In 1955, Cooperman and Willard began a study of more than 10,000 contemporary skulls. They searched the upper arches of the attritionally occluded skulls for anatomical reference points coinciding with "natures plane of occlusion". Observations determined that three anatomical points were in this plane, namely the two hamular notches and the incisive papilla. Hence the name, Hamular-Incisive Papilla plane or H.I.P. plane. ${ }^{14}$ They found the HIP plane to have a consistent relationship to the cranium. 
Schwartz indicated a need for scientific model analysis to standardize the diagnosis of the plane of occlusion in a uniform manner using maxillary anatomical reference points. He indicated that these maxillary reference points were related to Campers plane, defined by the hamular notches and anterior palatine papilla of the maxilla. ${ }^{15}$

Rich also observed a relationship between the occulsal plane and the HIP plane. He substantiated Cooperman and Willard's finding and found that in $84 \%$ of the cases studied, the range of divergence between the HIP plane and the attritional occlusal plane to be no more than 4 degees. ${ }^{16}$

Karkazis and Polyzois conducted a cephalometric study and confirmed Rich's observation that the HIP plane tends to parallel the occlusal plane with a divergence between the HIP plane and the occlusal plane of less than 9 degrees. ${ }^{17}$

Carson in 1996, described a new technique for all phases of occlusal dentistry called Orthocranial Occlusion. ${ }^{7}$ He says orthocranial occlusion occurs when the jaw closes straight and at right angles to the plane of occlusion. With the plane of occlusion parallel to the horizontal reference plane of the skull, the forces are balanced along the occlusal plane and within the cranium. He states the Hamular-Incisive Papilla (HIP) plane and the plane of occlusion tend to parallel each other and parallel to the surface of the earth. He recommended the Hamular-Incisive Papilla (HIP) plane for the analysis of patients maxillary occlusal plane and for the fabrication of dental prosthesis. Due to Carson's beliefs he developed an instrument called the Accu-Liner Orthopedic Analyzer and Articulator. It shows the clinician how far, in what direction, and what spatial relationship teeth and jaws have to the rest of the skull, to each other, and to the reference 
horizontal plane.

Dickerson in 1999, wrote traditional articulators are not designed to function as occlusal analyzers. He states they are not scientific instruments and can not be used as a level, plumb line, or measuring device, all of which are required for occlusal analysis and provided for in the design of the Accu-liner system. He states using this technology accurately aligns the teeth level to the horizontal reference plane(H.I.P. plane), which results in fewer post-op cementation complications and improve the longevity of the restorations because the forces are compressive rather than shearing. ${ }^{8}$

To current date there has been no studies to determine the relationship of the HIP plane to the true horizontal plane in a natural head position. 


\section{CHAPTER III}

\section{MATERIALS AND METHODS}

Ten subjects, 5 men and 5 women, ranging in age from 23 to 27 years with a mean age of 24 years, were selected from the West Virginia University School of Dentistry student population for inclusion in the study. The subjects acted as test subjects and served as their own controls. All subjects were screened by conducting an oral examination. The main criteria for selection were (1) verification of an intact maxillary arch and location of the incisive papilla and hamular notches. If the incisive papilla or hamular notches could not be located due to erupted $3^{\text {rd }}$ molars or anatomical variation, the subject was excluded from the study, (2) 24 natural teeth with a functional, acceptable occlusion ( no gross skeletal mal-relationships and able to function and masticate without pain), (3) a clinically stable and repeatable maximum intercuspation position, and (4) a normal range of motion. All subjects were required to read, review and sign the IRB approved consent form prior to initiation of the study. (a copy of the consent form is located in Appendix B).

In order to identify the H.I.P. plane on the lateral skull film, a radiographic stent was fabricated for each subject by making complete arch maxillary impressions using pre-packaged irreversible hydrocolloid [Jeltrate-Regular Set, L.D. Caulk, Division of Dentsply International, Milford, DE] with a water-powder ratio of 21 grams to $55 \mathrm{ml}$ of room temperate tap water. The alginate was hand mixed for 1 minute in a medium rubber 
flexible bowl and loaded into the appropriate sized metal-perforated stock tray. Alginate was placed directly on the incisive papilla and hamular notches by wiping with the finger just prior to the loaded tray being placed in the patient mouth for approximately 4 minute from the time of mix to insure an adequate final set. The alginate impression was removed, rinsed, and evaluated for completeness of the incisive papilla and hamular notches. Incomplete impressions were discarded and remade until all required anatomical areas were complete. The impressions where rinsed again under cold tap water, shaken dry, and disinfected by spraying with disinfection [Cavicide, Metrex Research Corp., Parker, CO] and placed in a sealed plastic head cover for 10 minutes. The impressions were removed and rinsed thoroughly and immediately cast using prepackaged Type IV die stone (Silky Rock; Whipmix Corp. Louisville, KY) mixed for 25 seconds under vacuum. The cast was separated from the impression after 45 minutes, trimmed on a cast trimmer and set aside to dry. Once the cast was retrieved, the incisive papilla and hamular notches were located and marked with a pencil. Metal balls $[4 \mathrm{~mm}$ diameter] were used as radiographic makers and luted to the dry cast with sticky wax. A vacuum matrix of $0.80 \mathrm{~mm}$ clear polypropylene [Ultradent Products Inc., South Jordon, UT] was made over the casts and attached metal balls. The material was allowed to cool for 10 minutes at room temperature and cut off the cast with a separating disc and laboratory handpiece. The metal balls were reinforced and secured with clear autopolymerizing orthodontic resin [Ortho-resin, L.D. Caulk, Division of Dentsply International, Milford, DE] with care to keep the resin off the intaglio surface of the radiographic stent. The stent was trimmed to allow a lateral skull radiograph to be made using standard techniques. All borders were polished on a lathe with a medium rag wheel 
and pumice. Once the radiographic stent was completed, it was sprayed with Cavicide and placed in a sealed plastic bag for 10 minutes. The stent was rinsed and stored in the bag with two tablespoons of sterile water. The bag was labeled with the subjects study number. Prior to the lateral skull radiograph the stents were tried into the patients mouth for verification that the metal balls contacted the hamular notch and the incisive papilla. This was done visually and with Pressure Indicating Paste(Mizzy Inc., Cherry Hill, CT).

With the radiographic stent correctly oriented in the mouth standard lateral skull radiographs of each subject were made, using a cephalostat. (Philips Stat-Oralix, Monza, Italy), range capability of 45 to $100 \mathrm{kV}$, at $20 \mathrm{~mA}$ for 0.04 to 5.0 seconds. Kodak Ortho L film (Eastern Kodak Company, Rochester, NY) was used with 60-inch source to object and 8 inch subject to film distance. The exposure was 75 to $80 \mathrm{kV}$ at $20 \mathrm{~mA}$ for 1.2 to 1.6 seconds in accordance with the subject's physical stature. The specific location of the skeletal landmarks on the lateral skull radiographs were all marked and measured by the chief investigator to reduce interexaminer differences during radiographic interpretation. The subsequent identification and construction of these reference points and craniofacial lines were recorded on orthodontic tracing paper using a straight edge ruler and the angles computed using a cephalometric protractor. The following reference lines were drawn on the acetate papers: (1) the HIP plane, (2) the Frankfort Horizontal plane. The point of intersection between these two reference lines formed the Frankfort horizontalH.I.P. plane angle that was measured using protractor to the nearest tenth of a degree and recorded.

The last part of the study involves a lateral profile photograph of the head. Each subject was measured, from the soul of the foot to the ear hole, using a retractable tape 
measurer and the measurement recorded in inches. The orbitale was palpated and marked on the skin using radiopaque makers consisting of metal balls (Beekley Spots, Bristol, $\mathrm{CT})$. A plumb line hung from the ceiling was used to define the vertical reference plane on the photographs. Each subject was instructed to stand as close to the plumb line with out touching the line. The photographs were taken with a digital camera (Minolta) on a standard tripod. The lens was moved vertically to correspond with the subjects' ear hole, which had been recorded in inches earlier. Each patient was standing faced toward a large window where they could look into the horizon and just prior to taking the picture the subject was instructed to "Stand erect, relax and look at the horizon". Two pictures were made for each subject. Once the pictures were made the following reference line was marked: (1) Frankfort horizontal plane. Using radiopaque markers as the orbitale and the top of the ear hole as the porion. The point of intersection between the Frankfort horizontal plane and the plumb line (true vertical plane) formed the angle between the Frankfort horizontal and the True vertical plane angle that was measured in degrees using a protractor. The angle between the Frankfort horizontal and the True horizontal plane was calculated by subtracting 90 degrees from the angle formed between Frankfort horizontal and the True vertical plane angle.

The lateral cephalometric radiograph was used to establish the relationship between the Frankfort horizontal reference plane [FH] and the HIP reference plane [HIP]. The lateral photograph was used to establish the relationship between the Frankfort horizontal reference plane $[\mathrm{FH}]$ and the true horizontal reference plane based on the plumb-bob (true vertical) in the photograph. The relationship of the HIP reference plane [HIP] to the true horizontal reference plane was established by angular measurements 
from the radiograph and photograph. The mean, standard deviations, and coefficient of variation of the craniofacial angles in the study were computed. 


\section{CHAPTER IV}

\section{RESULTS AND DISCUSSION}

\section{RESULTS}

The comparison of reference planes and the true horizontal in all ten subjects can be found in Table 1. The mean, standard deviation and coefficient variation were calculated for each reference plane and are found in Table 2. A graphic representation of the relationship of Frankfort horizontal plane to the True horizontal plane and H.I.P. plane to the True horizontal plane of each subject is shown in Figure 1 and Figure 2 respectively. The Frankfort horizontal plane varied from the True horizontal plane by a mean of 7.6 degrees, with a range of 19.5 degrees, a standard deviation of 7.05 degrees and a coefficient of variation of $92 \%$. The H.I.P. plane varied from the True horizontal plane by a mean of 5.5 degrees, with a range of 10 degrees, a standard deviation of 3.79 degrees and a coefficient of variation of $67 \%$. The relationship of the Frankfort horizontal plane to the H.I.P. plane was found to have a mean angle of 10.2 degrees, a range of 6 degrees, a standard deviation of 2.14 degrees. Due to the variability of the data in the sample no statistical significant results were found. 


\section{Table 1. Comparison of Reference Planes to the}

\section{True Horizontal Plane}

\begin{tabular}{|c|c|c|c|}
\hline Subjects & $\begin{array}{c}\text { Radiograph } \\
\text { F.H. Plane }<\text { H.I.P. } \\
\text { Plane }\end{array}$ & $\begin{array}{c}\text { Photograph } \\
\text { F.H. Plane }<\text { True } \\
\text { Horizontal Plane }\end{array}$ & $\begin{array}{c}\text { H.I.P. Plane } ~ \text { True } \\
\text { Horizontal Plane }\end{array}$ \\
\hline 1 & 8.5 & 14 & 5.5 \\
\hline 2 & 9 & 18.5 & 9.5 \\
\hline 3 & 13 & 9 & 3 \\
\hline 4 & 7 & 4 & 2 \\
\hline 5 & 8 & 10 & 10.5 \\
\hline 6 & 12 & 12.5 & 10 \\
\hline 7 & 12 & -1.5 & 8 \\
\hline 8 & 11 & -1 & 1.5 \\
\hline 9 & 9 & -1 & \\
\hline 10 & 12.5 & 11 & \\
\hline
\end{tabular}




\section{Table 2. Data Analysis}

\begin{tabular}{|c|c|c|c|c|c|}
\hline $\begin{array}{c}\text { Reference } \\
\text { Planes }\end{array}$ & Rank & $\begin{array}{c}\text { Coefficient } \\
\text { Variation }\end{array}$ & Mean & $\begin{array}{c}\text { Standard } \\
\text { Deviation }\end{array}$ & Range \\
\hline H.I.P. Plane & $\mathbf{1}$ & $\mathbf{6 7 \%}$ & $\mathbf{5 . 5}$ & $\mathbf{3 . 7 9}$ & $\mathbf{1 0}$ \\
\hline $\begin{array}{c}\text { Frankfort } \\
\text { Horizontal } \\
\text { plane }\end{array}$ & $\mathbf{2}$ & $\mathbf{9 3 \%}$ & $\mathbf{7 . 6}$ & 7.05 & $\mathbf{1 9 . 5}$ \\
\hline
\end{tabular}

Figure 1.

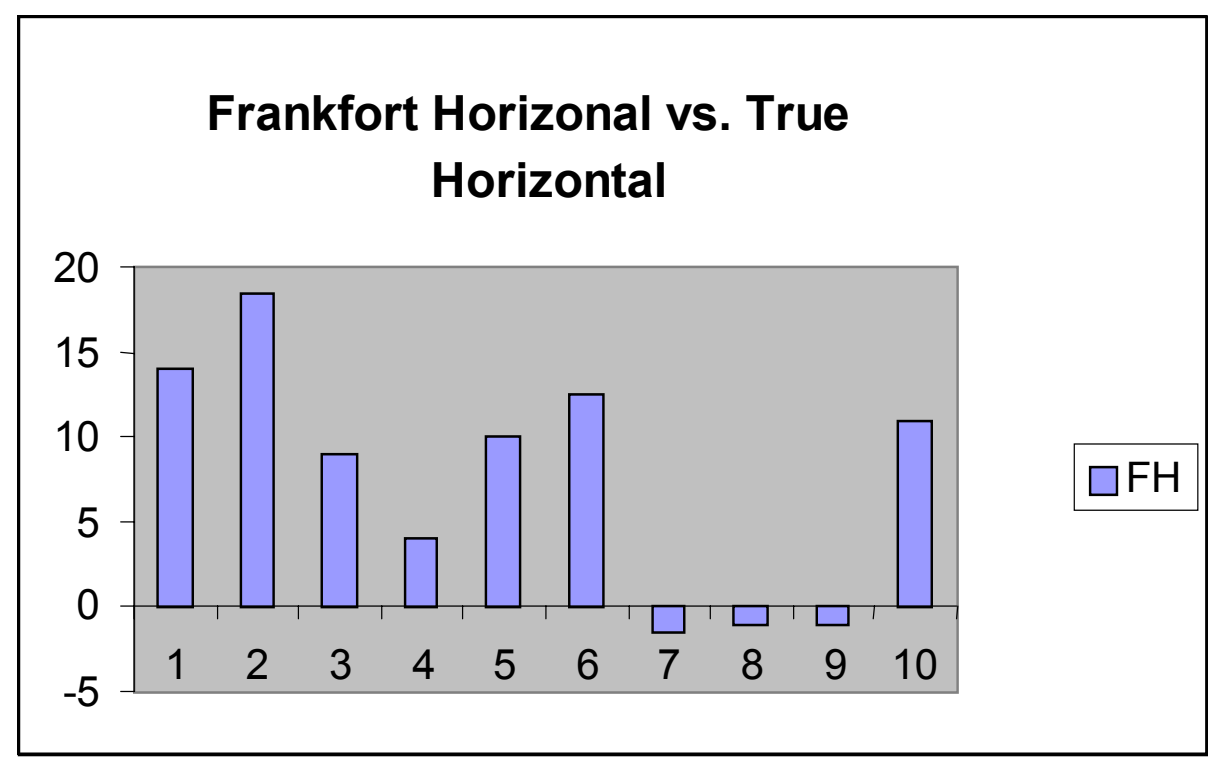


Figure 2.

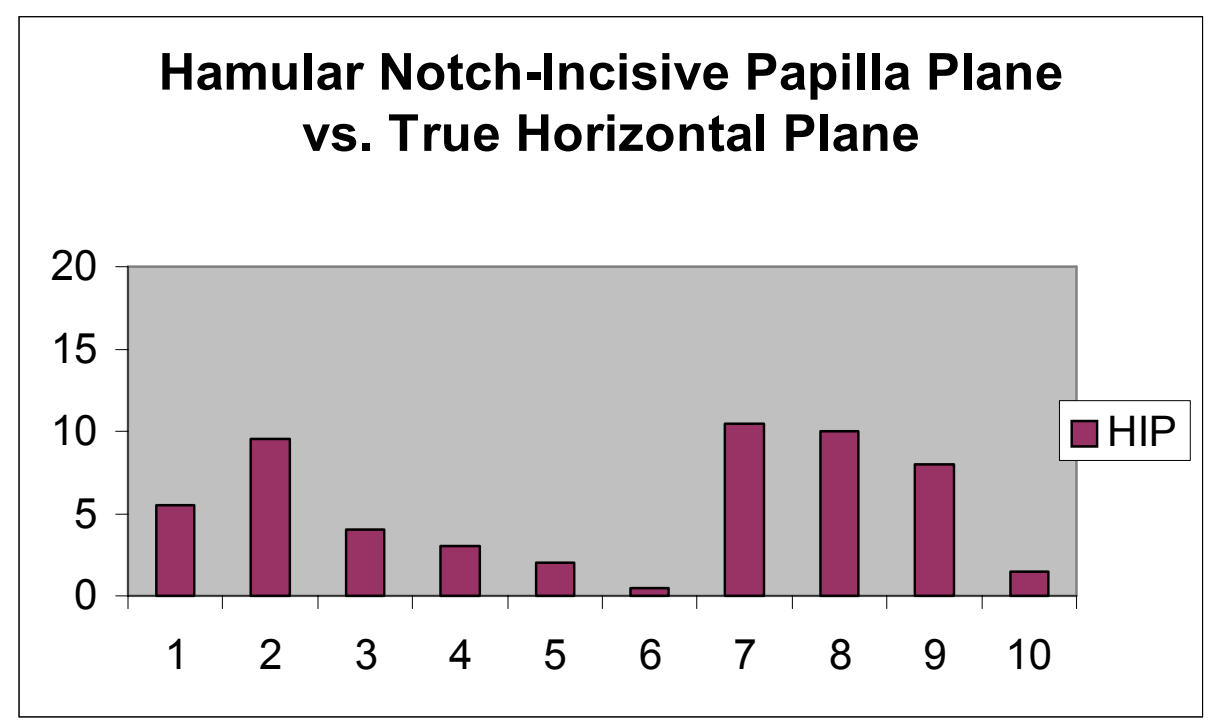

Figure 3.

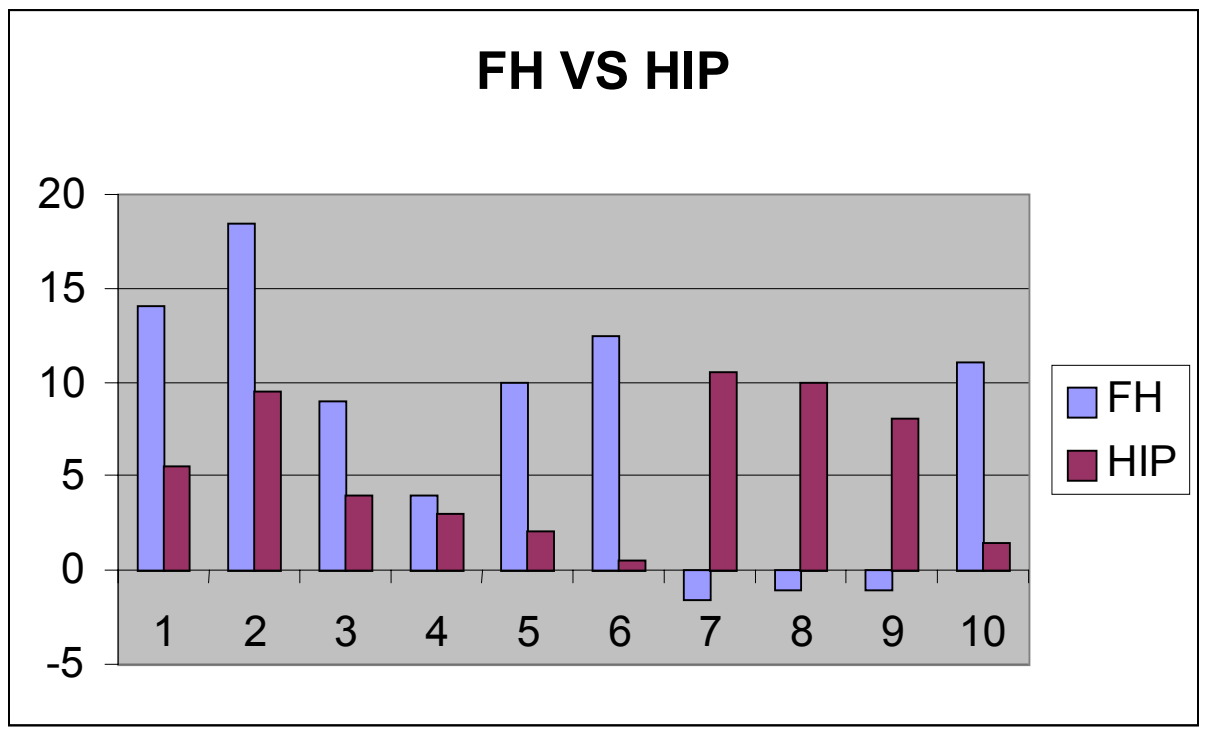




\section{DISCUSSION}

The goal of the mounted casts is to duplicate the patient in the dental laboratory for the purposes of diagnosis, problem solving, and treatment planning, and the fabrication of dental prostheses. Selecting a reference plane that is parallel to the surface of the earth while the patient is standing erect and assuming a natural head position is related to achieving the esthetic and functional goals in prosthodontic therapy. Historically, the most common reference plane used is the Frankfort horizontal plane, which has been defined as parallel to the true horizontal plane. H.I.P. plane has also been proposed as the true horizontal plane for orienting the maxillary cast to an articulator. In this study neither the H.I.P. plane nor the Frankfort horizontal plane were parallel to the true horizontal plane. There was a wide variation in both planes to the true horizontal among the subjects tested. There was no statically significant difference found in this study between either Frankfort horizontal plane or H.I.P. plane compared to the true horizontal plane.

Widespread research has been made for a reference plane, which in the natural head position would exhibit a constant relationship to the true horizontal plane. The term "Frankfort horizontal plane" is a misnomer and, as defined, the plane will usually not be parallel to the horizontal plane when the head is in the natural head position. Pitchford correctly observed the lack of parallelism between both Frankfort horizontal plane and axis-orbitale plane to the true horizontal plane. The results of this study were consistent with his findings that Frankfort horizontal plane formed an angle of 8 degrees with the True horizontal plane. Most articulator systems have incorporated these concepts into their designs. Since the porion point is not reproducible on the articulator, manufactures 
of articulators have substituted the axis for the porion. In this way, "the axis-orbitale plane was assumed to coincide with the Frankfort horizontal plane and by definition with the True horizontal plane." The manufacturers have incorporated these errors into their articulator design by placing the axes of the articulator and the orbitale indicators on a plane parallel to the true horizontal reference plane. The position of the maxillary model, after it is mounted in the articulator, is expected to be in the same vertical position as the maxillae with the subject's head oriented in the natural head position. However, the use of orbitale in conjunction with an articulator whose design assumption places the axis and orbitale indicator parallel to the true horizontal reference plane can result in substantial mounting errors. The use of anatomically steep horizontal reference planes will make it difficult to locate or appropriately align the cast with a suitable occlusal plane in the articulator.

Currently no studies have examined the relationship of H.I.P. plane to the true horizontal plane so we cannot compare our findings. This study only looked at the relationship between H.I.P. plane and the true horizontal plane not the relationship between the plane of occlusion to H.I.P. plane so any comparison with Rich's or Karkazis and Polyzois findings that the H.I.P. plane tends to parallel the occlusal plane was not possible. In this current study the H.I.P. plane was found to be closer to the true horizontal plane than Frankfort horizontal plane and the variation between test subjects was smaller for the H.I.P. plane than Frankfort horizontal plane. Cooperman and Willard first introduced the H.I.P. plane in 1955 when they where examining its relationship to the occlusal plane. Carson in 1996 stated "In a healthy body the symmetrical components of the skeletal structure should be parallel to each other: the base of the skull, the plane of 
occlusion, cervical vertebrae, shoulder girdle, thoracic vertebrae, lumbar vertebrae, pelvic girdle, knees, ankles, and the bones of the feet. He introduced the theory of Orhtocranial Occlusion it occurs when the plane of occlusion is orthogonally aligned to the forces of occlusion. It encompasses the relationship of the shape of the articulator eminences of the tempomandibular joints and the shape of the plane of occlusion. With the plane of occlusion parallel to the horizontal reference of the skull, the forces are balanced along the occlusal plane and within the cranium.. He feels dentists should look beyond the teeth and the tempomandibular joints and should become aware of the interrelationships of the whole structure: teeth, periodontal ligaments, joints, both maxillary and mandibular arches, cranium, and bony structure of the neck, back, and the rest of the body. The goal of the clinician is to create vectors of force at proper angles into the cranium to create harmony in the Cranio-Dental Complex, neuromuscular system, and craniosacral mechanism. He further claims when the plane of occlusion is misaligned and not related to the true horizontal the loading on the TMJ become unbalanced. This condition occurs even if the articular discs and the head of the condyle are in their optimal positions. The forces transmitted to the temporal bones and into the rest of the cranium also become unbalanced. This condition also creates disharmony in the neuromuscular system causing muscle tension on the cranial attachment points that can also create abnormal forces in the craniosacral mechanism. This unbalanced stress is said to cause pathological results affecting the teeth, periodontal ligament, bone, mucosa, cranium, and the muscle groups of the face, neck, shoulders, and the rest of the body. Carlson has introduced the Acculiner, a new dental articulator used to relate and accurately measure the interrelationships of the Cranio-Dental structure. Unlike the traditional articulators, which assume the 
Frankfort horizontal plane is parallel to the surface of the earth, the Accu-liner assumes the H.I.P. plane of the cast is parallel to the true horizontal plane in the natural head position. He claims using an anatomical correct horizontal plane (H.I.P. plane or True Horizontal plane of the skull with the head oriented in the natural head position), the cast can be more accurately aligned to the true horizontal reference plane. In order for the Cranio-Dental -Facial Complex to be in harmony and homeostasis, the plane of occlusion should be at right angles to the occlusal forces, as established by the H.I.P. plane.

According to this limited study, neither Frankfort horizontal plane nor the H.I.P. plane in $50 \%$ of the subjects were within 2 degrees of the true horizontal plane in the natural head position. This indicates that both planes can be parallel to the surface of the earth for individual patients in the natural head position. In this study, subjects where there was a great variation of both planes from the true horizontal plane may be explained by the individual variability of the natural head position. ${ }^{18}$

Based on this study, patients requiring mounted casts for prosthodontic treatment should first have their natural head position analyzed. This would allow the clinician to pick the correct reference plane that is parallel to the True horizontal plane based on each patient's natural head position. By leveling the facebow on the patient to a new third point of reference that is parallel to the True horizontal plane. This could help the clinician analyze the mounted casts and the occlusal plane relative to the True horizontal plane on an individual. This would eliminate mounting errors and assist in reaching the esthetic and functional goals of treatment. 


\section{CHAPTER V}

\section{SUMMARY AND CONCLUSIONS}

\section{SUMMARY}

Selecting a reference plane that is parallel to the surface of the earth while the patient is standing erect assuming a natural head position is related to achieving functional and esthetic goals in prosthodontic therapy. The goal of this study was to determine if either or both the H.I.P. or Frankfort horizontal planes are parallel to the surface of the earth in the natural head position. It was hypothesized that in the natural head position neither the H.I.P. plane nor the Frankfort horizontal plane are parallel to the True horizontal plane.

Ten subjects were evaluated in the natural head position with angular measurements made from lateral photographs and lateral skull radiographs to determine the relationship of these two reference planes to the True horizontal.

The research showed that neither the H.I.P. plane nor the Frankfort horizontal plane were parallel to the True horizontal plane. There was a wide variation in both planes to the True horizontal among the subjects tested. There was no statically significant difference found in this study between either the Frankfort horizontal plane or the H.I.P. plane when compared to the True horizontal plane. Some subjects 
were within 2 degrees of the True horizontal plane for both planes, however they both showed wide variations among the sample. The impossibility of locating a horizontal plane when the patient is in the natural head position may be inherent with the individual variability of this position.

\section{CONCLUSIONS}

This study showed neither the H.I.P. plane nor the Frankfort horizontal plane were parallel to the True horizontal plane. 


\section{REFERENCES}

1. Gonzalez, JB. and Kingery, RH. "Evaluation of Plane of Reference for Orienting Maxillary Cast on Articulator.” J American Dental Association 1976; 76:329336.

2. Carlson, James. "Criteria Used to Establish the Ideal Plane of Occlusal." J Functional Jaw Orthopedics 1996; 13:18-28.

3. Richards, Ow "Orientation of the Plane of Occlusion." J Prosthetic Dentistry $1990 ; 64: 31-36$.

4. Pichford, JH. "A Reevaluation of the Axis-orbital Plane and the use of Orbitale in a Facebow Transfer Record.” J Prosthetic Dentistry 1991; 66:349-355.

5. Ercoli, C., Graser, GN. and Tallents, RN. "Facebow Record without a third point of reference: Theoretical considerations and an alternative technique." $\mathrm{J}$ Prosthetic Dentistry 1999; 82:237-241

6. The Glossary of Prosthodontic Terms. $7^{\text {th }}$ ed., St. Louis: CV Mosby Co., 1999.

7. Carlson, JE. Introductory Manual to Othocranial Occlusion and the Accu-liner System. Accliner Products, 1998.

8. Dickerson, WG. And Carson, JE. "Predictable, Aesthetic, Full Mouth Reconstruction." Dent Today 1999; 50-55.

9. Foster, T.D. "The Use of the Face-Bow in Making Permanent Study Cast." J Prosthetic Dentistry 1959; 9:717-721.

10. Page, Harry. “The Cranial Plane.” Dental Digest 1955; 152-157. 
11. Wilkie, Noel. "The Anterior Point of Reference." J Prosthetic Dentistry 1979; 41:488-496.

12. Bailey, JO And Nowlin, TP. "Evaluation of the third point of reference for mounting maxillary cast on the Hanau articulator.” J Prosthetic Dentistry 1984; 51:199-201.

13. Stade, EH. "Esthetic Considerations in the use of face-bows." J Prosthetic Dentistry 1982; 48:253-260.

14. Cooperman, HN. And Willard, SD. "Studies of the Locuchheim Collection of Skulls.” New York: American Museseum of Natural History.

15. Schwetz, Robert. “A New Reference Plane." J Prosthetic Dentistry 1967; 45:438-446.

16. Rich, H. "Evaluation and Registration of the H.I.P. plane of Occlusion." Aust Dent J 1982; 162-168.

17. Karkazis, HD. And Polyzois, GL. "Cephalometrically Predicted Occlusal Plane: Implication in Removable Prosthodontics.” J Prosthetic Dentistry 1991; 65:258264.

18. Solow, BN. "Natural Head Position in Standing Subjects." Acta Odont Ocand $1971 ; 29: 591-607$ 


\section{APPENDIX A}

\section{Institutional Review Board Approval Form}

\section{West VirginiaUniversity}

The Institutional Review Board for the Protection of Human Subjects

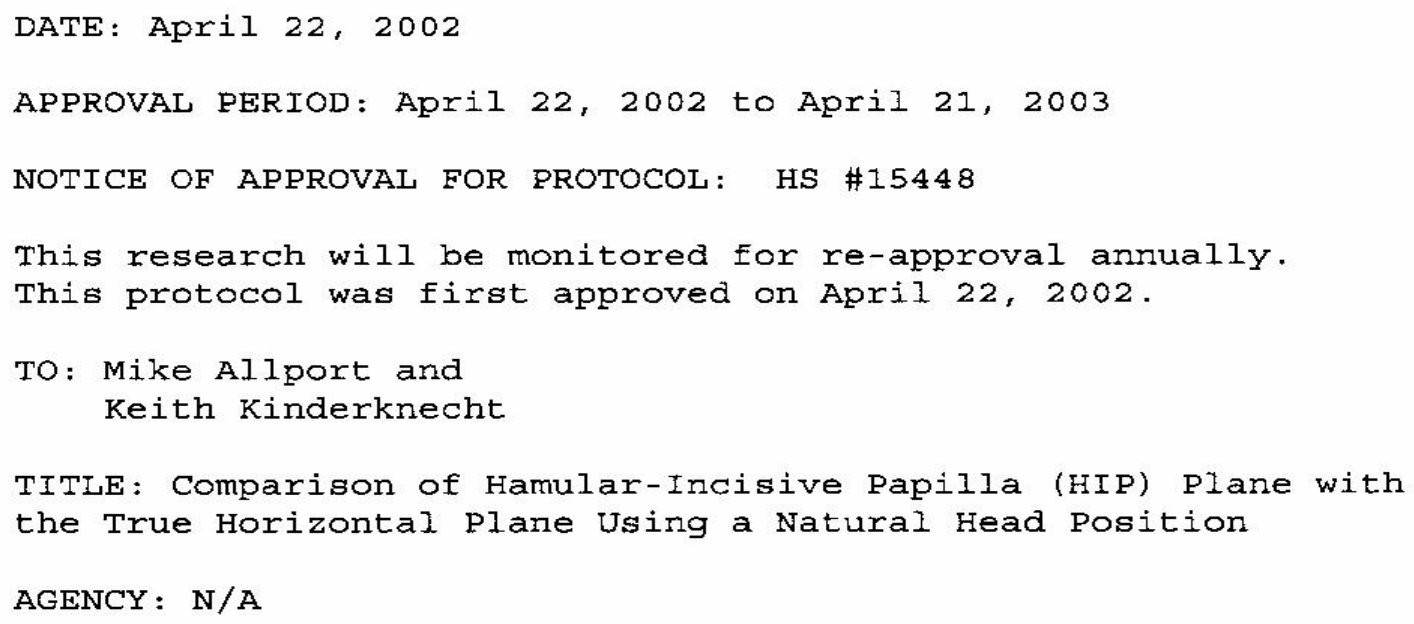

The Institutional Review Board for the Protection of Human Research Subjects (IRB) has approved the project described above. Approval was based on the descriptive material and procedures you submitted for review. Should any changes in your protocol/consent form be necessary, prior approval must be obtained from the IRB.

According to the code of Federal Regulations, Section 312.32, investigators are required to notify the FDA and the study sponsor of any adverse experience associated with the use of an investigational drug that is serious and unexpected. A serious adverse experience is considered any event that is fatal or life-threatening, is permanently disabling, requires inpatient hospitalization, or is a congenital anomaly, cancer, or overdose. An unexpected adverse experience is an event that is not identified in nature, severity, or frequency in the current investigator brochure. Any experience reportable to FDA and the sponsor must also be reported immediately to the IRB.

A consent form* $\mathrm{x}$ is___ is not required of each subject.

An assent form___ is $x$ is not required of each subject.

A recruitment ad has_has not_ $\mathrm{x}$ been approved.

\section{Chestnut Ridge Road, Foom 202 \\ PO Box 6845}

Morgantown, WV 26506-6845
Equal Opportunity/Affirmative Acțion Institutic 
Date: Apri1 22, 2002

Page -2-

Aliport

HS $\$ 15448$

Only coples of the consent and/or assent form with the IRB's approval stamp may be used with human aubject research. It is the responsibility of the investigator to submit a revised consent form for the IRB's approval should funding be obtained. This stamped consent form must then be used for subjects enrolled. A copy of each subject's signed Consent/Assent Form mutt be retained by the investigator and accessible to federal regulatory authorities for at least three years after the atudy is completed.

MarYan $J$. Turner

Seniot Program Coordinator

for Regulatory Compliance

MuT/baw 


\title{
APPENDIX B
}

\section{Consent Form}

\section{West VirginiaUniversity}

SCHOCL OF DENTISTKY

\author{
M5T vMPQHA twMTasm

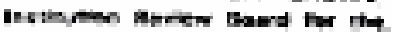

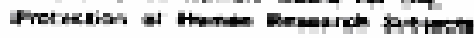

\section{CONSENT FOIRM INFORMATION FORM}

"Comparison of Hambles-Ineisive Papilla [HTPl Plone with the Trues Horizontal Plano Using a Nastaral Head Position"

Tntraduction

$\bar{L}$. , have been asked to participate in this regeereh study. which his been explained to me by Mike Allport, DDS or Keith Kinderknesht, DMD. This study is being cenducted to fulfill the degree of Master of Sxikenee in the Departmerst of Prosthodontics at Weat Virginia University.

\section{Purpose of the Study}

The purpose of ahis stady is to loam more about which roferences plabe- wowld be more useful in the fabtiestion of erowns.

\section{Deseription of Procediures}

This study invelves making upper jow impresaisn for the fabriegtion of a nouthpised. This thouchpiece will be comfortably placed in tho mowh daring a lateral skull $\mathrm{X}$-rdy. The last shing will be a photograph of the face on the right side while in a starnding prositión. None of the prequesed procedures aro experimentai in naturo and are routincly performed in a $\mathrm{g}$ encral dental prestise, This study wili talke 60 minutes bo complete. After this, I understand thst my partieipation in the study will be completed. Approximately 10 subjects are experted to participate in this study.

\section{Altemative}

I understivid. that I do not bave to particijate in this studiy.

\section{Benefits}

I understand that this astay is not expeoted to be of dircet bestlte to mo, but the knowledge gaines may be of benefit to others. I will reccive elinic participation hoars for being involved in this stady.

$04 / 02 / 02$
Pago 1 of 2

Initials $\quad$ Poic




\section{"Comparison of Hamular-Incisive Papilla [HIP] Plane with the True Horizontal Plane Using a Natural Head Position"}

\section{Risk and Discomforts}

There are no known or expected risks from participating in this study, except for the mild frustration associated with the performance of the impression of the mouth. Lateral cephalometric $\mathrm{X}$-ray, the ionizing radiation is very low making the risk minimal.

\section{Contact Person}

For more information about this research, I may contact Dr. Mike Allport at (304)-293-2612 at the School of Dentistry or his supervisor, Dr. Keith Kinderknecht at (304) 293-1656. For more information regarding my rights as a research subject, I may contact the Executive Secretary of the Institutional Review Board at (304)-293-7073.

\section{Confidentiality}

I understand that any information about me obtained as a result of my participation in this research will be kept as confidential as legally possible. I understand also that my research records, like hospital records, may be subpoenaed by court order or may be inspected by federal regulatory authorities. In any publication that results from this research, neither my name nor any information from which I might be identified will be published without my consent.

\section{Voluntary Participation}

"The decision to participate in this study is completely voluntary on my part. I understand that my class standing or grades will not be affected by refusal to participate or withdrawal from this study. My treating dentist has adequately answered all questions I have about this study, my participation, and the procedures involved. I further understand that I may withdraw this consent at any time and discontinue further participation in this study. I also understand that the investigator of this study may terminate my participation if he feels it's in my best interest.

Upon signing this form, I will receive a copy.

I willingly consent to participating in this research.

Signature of Subject

Signature of Investigator or Investigator Representative

\section{Date}

Date

Date
Time

Time 


\section{CURRICULUM VITAE}

\section{BIOGRAPHICAL DATA}

Name: David Michael Allport

Date of Birth: $\quad$ March 05, 1973

Place of Birth: $\quad$ Charleston, WV

\section{EDUCATION}

Fairmont State College

B.S. (Biology, Science)

1995

West Virginia University

D.D.S.

1999

West Virginia University

M.S., Certificate in Prosthodontics 2002 